\title{
MOVIMENTOS SOCIAIS E CIDADANIA NO BRASIL HOJE
}

Emil A. Sobottka*

\begin{abstract}
SÍNTESE - O texto parte da pergunta sobre como enfocar a problemática da cidadania e sua relação com a atuação dos movimentos sociais na sociedades atuais. Frente à diversidade de definições de cidadania e a pluralidade morfológica dos movimentos, a proposição é mudar o enfoque, centrando-o em modelos de análise global da sociedade, no marco de propostas contratualistas. Reformas recentes no Brasil, com a descentralização ainda em curso, oferecem a oportunidade de visualizar o enfoque e mostrar por que onGs e novas formas de filantropia crescente entram em conflito com os movimentos sociais.
\end{abstract} PALAVRAS-CHAVE - movimentos sociais, cidadania, contratualismo.

\begin{abstract}
The text develops from the question of how to look at the problem of citizenship and its relationship with the action of the social movements in current societies. Because of the diversity of definitions of citizenship and the morphological plurality of the movements, the proposal is to change the emphasis, focussing on models of global analysis of the society, in the mark of contractual proposals. Recent reforms in Brazil, with the decentralization still going on, offer the opportunity to visualize the focus and show why ONGS and new forms of growing philanthropy conflict with social movements.

KEY WORDS - social movements, citizenship, contractualism.
\end{abstract}

\section{Introdução}

$\mathrm{Na}$ década atual, há um termo que passou a estar presente em praticamente toda manifestação de movimentos sociais populares no Brasil e nos demais países da América Latina: cidadania. Ele vem acompanhado de uma aura de positividade, como se condensasse o que de mais importante pudesse ser almejado para uma sociedade ainda por construir. Ocupa o lugar dado nas décadas anteriores a outros termos como democracia e sociedade civil. Os movimentos sociais populares não são os únicos a utilizá-lo, mas é neles que está mais fortemente presente e se concentra a presente análise.

A cidadania é por eles apresentada como algo a ser conquistado, construído e fortalecido, remetendo a um contexto conflitivo. Ela se opõe a uma realidade atualmentẹ tida como dada, caracterizada pela exclusão e marginalização. Uma observação acurada mostra que, no uso do termo, os conteúdos em questão podem ser significativamente distintos (cf. Sobottka, 1997).

* Sociólogo e cientista político, doutor pela Universidade de Münster, professor na PUCRS.

\begin{tabular}{|l|l|l|l|l|l|}
\hline VERITAS & Porto Alegre & v. 43 & $\mathrm{n}^{\circ}$ especial & Dezembro 1998 & p. 193-203 \\
\hline
\end{tabular}


Referido ao mundo do trabalho, o termo cidadania significa ter uma ocupação aceitavelmente remunerada, na forma de emprego ou de outra modalidade. No âmbito da política, consubstancia-se na participação, que por sua vez abarca todo um complexo de aspirações que vão desde a escolha dos ocupantes de cargos diretivos até a tomada de decisões e a gestão, passando pelos resultados das políticas públicas, sociais ou gerais. Para o cidadão consumidor, a ênfase é colocada, de um lado, na renda que lhe permita cobrir os custos dos produtos e serviços socialmente necessários para um padrão mínimo de vida e, de outro, na garantia de que, na relação contratual firmada com o ato da compra, os termos implícitos sejam assegurados em sua plenitude. No âmbito da seguridade, cidadania igualmente vem associada a uma dupla referência: assegurar que benefícios tidos como de direito sejam mantidos e levar a que outros que não estejam ainda legalmente definidos passem a sê-lo. Dois outros conteúdos, reivindicados em contextos espećíicos por movimentos sociais, referem-se à segurança jurídico-formal de um estado de direito e à nacionalidade de povos não ou apenas parcialmente integrados à nação brasileira. Por fim, nas relações em sociedade, cidadania veicula a busca de especificação e reconhecimento de laços aglutinadores e distintivos em forma de identidade coletiva e emancipação.

Com estes exemplos, já se evidenciam a amplitude e o caráter difuso das expectativas associadas à cidadania nos movimentos sociais populares. Eles devemse em boa medida à dificuldade inerente à própria definição terminológica. Não há pretensão nem possibilidade de equacioná-la aqui, por isso será apenas brevemente referida. Mas há que se perguntar como enfocar a problemática da cidadania e sua relação com a atuação dos movimentos sociais nas sociedades atuais. A proposição é mudar o enfoque: não se centrar na discussão dos movimentos, mas em modelos de análise global da sociedade e confrontá-los com transformações recentes, em larga medida ainda em curso, no Brasil. Para concluir, será então feita a tentativa de relacionar as reformas em andamento no Brasil com perspectivas dos movimentos sociais populares na defesa da cidadania.

\section{1 - Cidadania ou cidadanias?}

Cidadania pode ser definida, antes de mais nada, como "direito a ter direitos" (Vieira, 1997). A despeito de já ter existido na antigüidade, seu uso moderno está associado ao triunfo do racionalismo sobre o tradicionalismo, com o qual a vida em sociedade passou a ser concebida preponderantemente como resultado de um contrato horizontal, regido por regras de uma associação entre indivíduos, e não de uma relação vertical entre governantes e súditos. Essas regras necessariamente deveriam ser explícitas e integradas como um todo formalmente coerente.

No contratualismo, onde essa concepção foi amplamente debatida, percebeuse adequadamente que a cidadania trazia consigo uma contradição fundamental entre o individual e o coletivo, o particular e o universal. Seja nas concessões, seja nas demandas, a conciliação foi vista como potencialmente desestabilizadora, requerendo, no limite, a opção pela preponderância de um ou outro como princípio fundante. Em Hobbes e Rousseau, embora com distinções nitidas, a primazia foi colocada no coletivo: aquele colocou-a no Estado, este na comunidade. Locke, ao 
contrário, colocou-a no individual. Não era uma preocupação nova; ela já estava presente na filosofia grega e medieval, mas adquiriu novo enfoque ao ser colocada como questão do homem com a sociedade em que vive e com seu governo, constituindo-se em objeto central da cidadania civil.

Esta distinção característica das sociedades ocidentais modernas não se impôs plenamente como princípio organizativo na América Latina. Morse, num livro que gerou grande polêmica no Brasil, defendeu que a diferença de postura com relação à responsabilidade do estado na realização dos direitos de cidadania em países como os Estados Unidos e no Brasil advém da influência cultural distinta entre a tradição anglo-saxã, de corte calvinista, voltada de costas para o Estado, e a ibérica, de raizes tomistas, com ênfase numa cidadania referida ao coletivo, consubstanciado no Estado (Morse, 1988). Expressão contundente dessa diferença seria justamente a individualização extrema dos primeiros, enquanto os últimos teriam preservado referências públicas. Para Morse, a individualização foi extremada e seus efeitos negativos desagregadores poderiam ser superados nos Estados Unidos ou evitados na América Latina mediante a valorização da tradição ibérica.

Seus contestadores, sobretudo Simon Schwartzman, foram enfáticos em rejeitar a alternativa de uma valorização positiva da tradição ibérica, vendo tãosomente no que definiam como modernidade, em oposição à cultura tida como tradicional, o futuro aceitável para o Brasil e outros países latino-americanos (Arocena, Léón, 1993; Oliveira, 1991). Hoje, como será visto logo abaixo, advoga-se crescentemente no âmbito de um novo contratualismo por opções ecléticas, que atenuam a contradição. Estas proposições partem do individuo emancipado como pressuposto e perguntam-se pelo adequado grau de relações com instituições de caráter coletivo.

No seu estudo clássico sobre a cidadania, Marshall defende a existência de três gerações distintas de direitos de cidadania (Marshall, 1967). Os de primeira geração seriam os direitos civis e políticos, os de segunda seriam sociais, e os terceiros seriam aqueles cuja titularidade é coletiva. Seu surgimento estaria associado a três momentos históricos distintos: a revolução liberal, a ascensão da social-democracia e o movimento terceiro-mundista. Os primeiros coincidem aproximadamente com os direitos humanos declarados pela onU em 1948, enquanto os demais correspondem ao que a onU acolheu em meados dos anos 60 e o movimento dos países não alinhados defendia desde então nas conferências da Unctad. Diferente de concepções seletivas da antigüidade, cidadania atualmente é tida como "universal", extensiva a todos os seres humanos partícipes de determinada sociedade. Mas Marshall é criticado por sua ênfase num desenvolvimento linear da cidadania e a vinculação desta à estratificação social. A distinção entre gerações não se tornou consensual no debate acadêmico. O esvaziamento do movimento dos países não alinhados e das conferências da Unctad tirou a força dos principais impulsionadores oficiais dos direitos coletivos apontados por Marshall. A crise dos Estados de bem-estar social e as ditaduras mostraram também que os demais direitos de cidadania não são conquistas universais da Humanidade que, uma vez obtidas, se tornam irreversiveis. 
Não obstante, é amplamente aceita a possibilidade de diferenciar fundamentalmente entre a cidadania enfocada como conjunto de direitos civis e políticos, e a cidadania como conjunto de direitos sociais, sejam eles individuais ou coletivos. Os primeiros, em sintonia com a doutrina liberal pura do Direito, pressupõem um sistema jurídico definido pela sua forma e não por conteúdos ou valores implicados em suas normas. ${ }^{1}$ São direitos fortemente defensivos do indivíduo contra o Estado e seu governo. Os segundos, em sua origem fortemente vinculados ao projeto social-democrata europeu, apóiam-se na intervenção ampla do Estado e de organizações multilaterais, como partido compensatório no conflito de interesses em torno da partilha dos recursos na sociedade. Estão profundamente afetados pela crise de legitimidade do Estado de bem-estar social. Uma terceira vertente vem assumindo cada vez maior importância também na América Latina e envolve direitos imateriais, de emancipação e expressão. Calcada em projetos difusos de sociedade comunitarista segmentada, preenche a cidadania com conteúdos e valores a serem conquistados pelos próprios interessados e resiste a uma cooperação sintomática com o poder estatal. Tem em alguns movimentos sociais seus principais portadores e é ainda utópica no sentido mannheimiano.

Por conseguinte, pode-se afirmar que há uma pluralidade de cidadanias. $O$ uso do termo no singular tem possivelmente mais a ver com a vontade afirmativa num contexto de disputa por legitimação de diferentes projetos de sociedade do que com a precisão na definição đo conteúdo.

\section{2 - Análises giobais da sociedade}

A discussão da cidadania relacionada com os movimentos sociais populares cedo ou tarde esbarra na pluralidade, virtualmente infinita, de movimentos, tendências e grupos, cada qual com suas características e aspirações. Frente a isto, a proposição aqui é abordar a questão por um outro ângulo, qual seja, a partir de modelos de análise da sociedade que, espera-se, permitam superar a fragmentação a que a morfologia dos movimentos leva e ao mesmo tempo apontar para espaços de atuação possíveis. São usados três enfoques: de Cohen e Arato, de Offe e de Santos. Eles têm proposto análises globais da sociedade que auxiliam neste empreendimento.

O modelo de análise da sociedade proposto por Habermas em sua teoria da ação comunicativa foi acolhido em amplos debates por algumas virtudes, mas também por limitações. Uma destas limitações foi precisamente a atribuição de um papel preponderantemente (se não meramente) defensivo aos movimentos sociais que, ao mesmo tempo, eram tidos como os principais atores capazes de impulsionar o resgate do projeto da modernidade. Nisso, Habermas revelou a restrição de sua preocupação a uma cidadania com direitos políticos e civis por um lado e imateriais expressivos por outro. Em parte porque pressupunha como resolvidas, em princípio, as necessidades materiais básicas, associadas a uma cidadania com direitos sociais. ${ }^{2}$

Para maiores detalhes, ver o texto de Hans-Georg Flickinger nesta edição e Offe, 1991, p. 151-167.

2 Com esta afirmação não se desconhece as análises de Habermas e Offe a respeito da crise do estado de bem-estar social. Ela refere-se unicamente ao pressuposto habermasiano de que o sub- 
Cohen e Arato partiram deste modelo, com subdivisão em subsistemas da economia e da política (do Estado) e mundo da vida, complementando-o com a distinção entre uma esfera pública e uma privada (Arato, Cohen, 1994). Com este acréscimo, o mundo da vida habermasiano foi dividido numa esfera pública (da participação e opinião pública) e outra privada (família); analogamente, a economia é vista como a esfera privada e o Estado como a pública no sistema. Os autores propõem então complementarmente um conceito de sociedade civil, no qual agregam o conjunto das instituições e organizações do mundo da vida. A sociedade civil é responsável não apenas por defender o mundo da vida da colonização sistêmica, mas de impulsionar a transformação da sociedade também propositivamente. "Os atores da sociedade civil organizados em movimentos sociais cumprem função pública, absorvendo a ação comunicativa existente no mundo da vida e levando-a ao nivel da esfera pública. Defendem o interesse público e se constituem como instância crítica e controle do poder" (Vieira, 1997, p. 61). Difere a sociedade civil dos lobbies por defender aquela os interesses coletivos e públicos enquanto estes defendem os interesses privados.

Este modelo de análise permite apreender teoricamente aspectos fundamentais da relação dos movimentos sociais com outros atores, de atuação centrada preponderantemente na economia ou na política. Na defesa das diversas formas de cidadania, os movimentos sociais poderão encontrar combinações bem distintas de aliados e opositores; na luta por direitos civis e políticos, por exemplo, têm potencialmente outros aliados que na busca por conquistas econômicas e sociais. Uma limitação grande deste modelo é não distinguir na sociedade civil as múltiplas formas de ONGS dos movimentos sociais. Para a situação atual no Brasil, esta distinção é necessánia porquanto permite abordar conflitos potenciais de interesse entre eles.

Um segundo modelo de análise global a ser aqui acolhido foi proposto por Offe. Num seminário sobre Sociedade e a reforma do Estado, ele delineou arranjos possíveis na presente transição pela qual passam diferentes sociedades (Offe, 1998). Em estreita vinculação com Weber, ele elabora sua proposição em torno da relação entre Estado, mercado e comunidade, que teria correspondência com os modos como o indivíduo coordena suas ações: razão, interesse e paixão. Cada um deles dá origem a padrões de ordem social, permitindo que a justiça nas relações sociais assuma um significado operacional distinto: como direitos iguais, resultados e necessidades. As doutrinas puras a eles relacionadas são respectivamente a social-democracia, o liberalismo e o comunitarismo. É em torno delas que se debateu a Humanidade neste século.

Para Offe, o desvirtuamento das relações sociais é tributado à ênfase unilateral em uma ou duas dessas esferas. Ela se dá em boa medida por causa do lobby que cada uma tem e dos estímulos a elas inerentes: poder, dinheiro e solidariedade. A unilateralidade gera patologias como excesso de estatismo, ingovernabilidade, confiança em ou controle excessivo de mecanismos de mercado, comunitarismo exacerbado ou negligência das comunidades e identidades. Qualquer destas patologias implica crise. A proposição do autor é a busca por um mix, um equilíbrio contextualmente adequado entre Estado, mercado e comunidade.

sistema economia estaria apto a suprir adequadamente as necessidades materiais básicas na sociedade, defendido desde o final dos anos 60 . 
Na distinção dos fundamentos da ordem social e no traçado das conseqüências que os desequilíbrios possiveis provocam está o mérito de Offe nesta exposição. Mostra como as diferentes combinações geram tipos de sociedades com patologias específicas. Falta surpreendentemente, no entanto, colocar as diferentes esferas em relação; falta tematizar mais detalhadamente a questão de como seria definido, gerado e mantido o equilíbrio adequado do mix proposto. A relação entre esferas é, efetivamente, a relação entre agentes com atuação preferencial destacada dentro delas: partidos políticos, agentes econômicos e movimentos sociais. Esta complementação traria à tona as tensões inerentes à transição; revelaria a forma como projetos de reforma da sociedade e noções de cidadania estão ligados a portadores sociais. Revelaria que a dosagem do mix não é uma questão técnica, mas definida no âmbito das disputas políticas.

Ao buscar equacionar esta mesma questão da intrínseca relação entre projetos de sociedade e cidadania, Santos, no terceiro modelo aqui apresentado, retoma tanto Weber como os contratualistas (Santos 1997, cap. 4 e 9). Para ele, a sociedade moderna, como projeto, está apoiada em dois pilares: o da regulação e o da emancipação. A regulação constitui-se dos princípios do Estado, do mercado e da comunidade, respectivamente referidos a Hobbes, Locke e Rousseau. A emancipação é constituída pela articulação entre as racionalidades moral-prática, cognitivo-experimental e estético-expressiva. $\mathrm{O}$ equilíbrio tanto entre os dois pilares como entre os três princípios que compõem cada um deles é tido como essencial para a sociedade.

Diferente dos modelos interpretativos vistos acima, no entanto, o equilíbrio ocorre em dois planos: "O equilíbrio pretendido entre a regulação e a emancipação obtém-se pelo desenvolvimento harmonioso de cada um dos pilares e das relações dinâmicas entre eles" (p. 236). Com isso, o autor realça que tanto no Estado como no mercado e na comunidade o indivíduo está submetido a regulações que limitam sua ação, mesmo quando este segue racionalidades específicas para cada esfera.

$\mathrm{Na}$ interpretação de Santos, a modernidade foi frustrada como realização de projeto de sociedade porque o pilar da regulação foi exacerbado em seu desenvolvimento e o da emancipação atrofiou-se. Na regulação, os princípios do Estado e do mercado tomaram-se como predominantes, enquanto o da comunidade ficou relegado à insignificância.

A cidadania é vista por Santos como o mecanismo regulador da tensão entre as prioridades sociais. Segundo a predominância do princípio de turno, ela assume características específicas. A universalização sob a lógica do Estado ignora as diferenças nas subjetividades; o princípio do mercado convive bem com uma cidadania civil e política, mas conflitua com exigências da cidadania social. Uma relação mais equilibrada entre os princípios do Estado e de mercado, forçada pelo princípio comunitário, seria a reforma necessária, mas sem desdenhar o equilíbrio entre cidadania (regulação) e subjetividade (emancipação). Santos alerta para duas distorções que historicamente acompanharam conquistas importantes. A primeira surgiu no contexto das conquistas sociais sob a égide do princípio do Estado: implicou uma submissão dos setores beneficiários à obrigação política num Estado 
regulador. A segunda, na crise expressa no movimento estudantil dos anos 60 contra esta regulação, trouxe a primazia da subjetividade sobre a cidadania, do particular sobre o universal.

Os movimentos sociais teriam, para Santos, as melhores condições para impulsionar a mudança corretiva nas sociedades atuais. A maneira como os movimentos se caracterizam e como definem a cidadania que impulsionam depende do contexto. Tendencialmente nos países centrais sua luta seria por democracia participativa e valores pós-materialistas, enquanto na América Latina a ênfase recairia na democracia participativa com atendimento de necessidades básicas. Os movimentos sociais no Brasil são vistos pelo autor como a meio caminho entre as duas situações. Num mundo crescentemente globalizado, movimentos sociais de países assim poderiam impulsionar o resgate de componentes comunitários nos projetos de sociedade, aprofundando o alcance da cidadania.

Tanto Offe como Santos advogam a necessidade de um novo contrato social. Nele seria redefinida a configuração da sociedade segundo o grau de prioridade para cada uma das três esferas ou princípios por eles recuperados no contratualismo clássico. Cohen e Arato, por outro lado, apóiam-se na clássica noção de uma sociedade civil capaz de corrigir mazelas do sistema, definindo-a de forma inovadora. São propostas que trazem importante contribuição para a análise das sociedades contemporâneas na ótica das expectativas relativas à cidadania. Mas, como bem admitiu Offe, suscitam a pergunta pelas condições de transição efetiva para uma sociedade em que os vários aspectos da cidadania - ou as várias cidadanias possam ser equilibradamente cumpridos. Terão os movimentos sociais, em especial os de recorte popular, condições para interferir tão fortemente na definição dos rumos da sociedade como deles é esperado? A avaliação de suas possibilidades foge aos objetivos deste estudo; pretende-se, não obstante, que a análise a partir de modelos globais da sociedade permita pelo menos visualizar mais precisamente a teia de racionalidades implicadas.

\section{3 - Descentralização e cidadania no Brasil}

Ao decompor as sociedades contemporâneas basicamente em três esferas, cada qual com racionalidades e dinâmicas distintas, as análises acima lançam luz sobre a relação necessária entre lógicas distintas que nelas convivem e se confrontam. Isso permite aos movimentos sociais interessados na superação da ordem dada procurarem espaços especíicos e eficazes para sua intervenção. Sob a ótica destes modelos teóncos pode-se analisar as tendências de descentralização e participação em curso atualmente no Brasil. Ela aqui será feita colocando em relevo alguns dos objetivos dos movimentos sociais populares expressos em termos de cidadania.

O ciclo mais recente de reformas no Brasil foi inaugurado com a luta por democratização e parece estar longe de seu final (cf. Diniz, 1997). Numa primeira etapa, provisoriamente concluída com a promulgação da Constituição de 1988, as reformas estavam centradas na cidadania clássica, dos direitos civis e políticos. Envolveram diversas conquistas democráticas como eleições livres e regulares, liberdades diversas, garantias básicas de um estado de direito. Definiu-se nela o desenho básico de um Estado garantidor de direitos formais. 
Outra etapa da reforma esteve em curso paralelamente durante toda a década dos anos 80. Visava garantir direitos sociais e econômicos associados e constituir uma cidadania mais igualitária. Resultou na inserção, na Constituição, de uma ampla gama de direitos que Marshall identificaria como de segunda geração. A despeito de problemas relativos à sua regulamentação e acessibilidade efetiva, estes direitos estão desde então legitimados e formalmente reconhecidos na sociedade brasileira. Mas a esfera da sociedade evocada foi outra: buscou-se um Estado forte que preenchesse a cidadania formal com compensações advindas da esfera econômica. Foi o auge dos direitos sociais universais (Lessa et al. 1997).

Paralelamente foram incorporados direitos de cidadania que, na distinção feita acima, se encaixam no terceiro grupo: direitos imateriais e de emancipação. O lugar da população indígena e de outros segmentos populacionais, a questão ambiental, objetivos culturais da nação, novos espaços de reconhecimento das mulheres são alguns exemplos. Embora inseridos concomitantemente com os direitos sociais e econômicos, distinguem-se por estarem preponderantemente calcados em pressupostos comunitários. Isso implica que a própria disputa em torno deles assuma outra dinâmica.

Uma terceira etapa da reforma, ainda em pleno curso, consiste em impulsos significativos rumo a uma descentralização, com sua diversidade de modalidades (Stein, 1997). Houve descentralização no sentido de um amplo processo de privatização, que retirou do Estado boa parte de sua atuação econômica. Em diversos segmentos da seguridade social, o Estado reduziu suas atividades a ponto de não suprir a demanda, abrindo espaços para a mercantilização de serviços formalmente definidos como direitos sociais públicos. Uma parte não mercantilizada foi externalizada para organizações filantrópicas e sociais. Também houve transferências significativas de responsabilidades entre as esferas de governo, em especial para os municípios. Topicamente foram abertos espaços de participação direta dos cidadãos em várias instâncias, destacando-se os conselhos em diversos níveis de governo. O tom predominante, pelo menos segundo a retórica do governo, é a redução de custos e o aumento da eficácia, tendo o mercado e suas exigências como padrão de aferição (cf. Bresser Pereira, Spink, 1998).

Ao perguntar pelos principais impulsionadores das reformas, constata-se que foram composições muito distintas, nas quais o papel dos movimentos sociais teve importância variável. Na primeira etapa, eles estiveram amplamente envolvidos, valeram-se de mediações politicas e associaram-se a inúmeros outros agentes, mas não foram os definidores do rumo tomado pelas reformas. Já a inserção tanto de direitos sociais como de direitos imateriais e de emancipação na Constituição teve nos movimentos sociais um de seus principais portadores, junto com sindicatos e outros setores da sociedade, formando uma aliança que fez uso eficaz da mediação política.

$O$ processo de descentralização que seguiu foi marcado por um acirramento da disputa pela definição das reformas. Ao lado dos movimentos sociais populares e seus aliados, tomaram impulso forças sociais contrárias à presença do Estado na economia e à universalização de direitos sociais. Alguns dos direitos recém reconhecidos foram ignorados, outros implantados apenas timidamente. Com a vitória de Fernando Collor, a disputa ficou decidida: as forças contrárias à cidadania so- 
cial se impuseram amplamente no Brasil e colocaram os movimentos sociais populares e seus aliados na defensiva. A economia passou a ser a esfera dominante na sociedade brasileira. Os governos que seguiram não alteraram esta situação; 0 atual levou-a inclusive ao extremo ao subordinar de fato toda a dinâmica da estrutura governamental aos ministérios econômicos.

As conseqüências desta etapa da reforma sobre os movimentos não têm sido univocas. De um lado, foram abertos espaços de participação na execução e gestão e em alguns casos mesmo na definição de diversas políticas, e colocados à disposição de organizações não governamentais volumes significativos de recursos antes não acessiveis no país. A responsabilidade pelas coisas públicas pôde ser partilhada; transparência e prestação de contas tornaram-se parte importante do processo político-administrativo. Por outro lado, a exigência de profissionalização das organizações levou, com freqüência, a um distanciamento destas de suas bases, produzindo como efeito um grande número de onGS autônomas, primariamente agências prestadoras de serviços governamentais e cada vez menos representantes legítimos dos movimentos (Gohn, 1997). Foi um processo amplo de cooptação que não ocorreu sem a ciência das onGs, pois seus dirigentes há anos vinham discutindo a questão (cf. Pnud, 1992). Ademais, a positividade de sentido associada às onGs levou a sua multiplicação desenfreada: ensejou a criação de novas organizações freqüentemente sem vinculação com movimentos sociais e motivou muitas organizações antes definidas por outros qualificativos e criadas com outro caráter, como filantrópicas, por exemplo, a apresentarem-se como ONGS.

Houve uma proliferação de agentes livres, descomprometidos com movimentos, descaracterizando a especificidade que onGs tinham no país. Não se legitimam pela representatividade de segmentos sociais, não têm na mobilização de recursos e nas ações não rotineiras o seu centro de gravidade, nem têm condições políticas de apoiar na transgressão limitada das regras da sociedade sua estratégia política. A racionalidade norteadora no segmento das ONGS que vem ganhando visibilidade e espaço de legitimidade tornou-se sempre mais orientada por indicadores econômicos e administrativos e menos por ação coletiva, solidária e política. Com isto, mais e mais oNGs, este fenômeno organizativo típico da comunidade em busca de afirmação da cidadania em suas variadas formas, situam-se entre os agentes econômicos como empresas, ou na esfera política como Estado travestido.

\section{4 - Perspectivas}

A diversidade nas concepções de cidadania e a pluralidade dos próprios movimentos sociais assim como a dinâmica das reformas em curso no Brasil inviabilizam a pergunta genérica sobre a situação dos movimentos sociais populares e as perspectivas de alcançarem seus objetivos. Por isso, a trilha aqui seguida foi a de observar o processo de reformas no Brasil com o emprego heurístico de análises globais da sociedade. Destas foi acolhido que os movimentos, caracteristicamente comunitários e distintos dos agentes econômicos e administrativos, têm um proprium que lhes confere esfera, significados e alternativas de ação inconfundiveis. É a partir deles que, nas diversas etapas de reforma, apresentam-se cenários específicos e estratégias políticas possiveis. 
As análises das implicações da descentralização e das mudanças na concepção de sociedade são divergentes. Esgotadas estão pela simploriedade e pela inviabilidade politica aquelas que insistem num único curso para as ações, como, por exemplo, a via da tomada do poder de Estado. Outras apontam em direções certeiras, mesmo que passiveis de ressalvas. A duas delas será feita referência aqui.

Alguns representantes das ONGS são entusiásticos defensores daquilo que definem como sendo o surgimento de um terceiro setor, que seria privado em sua origem mas público quanto às finalidades (cf. Fernandes, 1994). Nesta ótica, as atividades das ONGS são vistas com certo pragmatismo, enfatizando que seriam mais eficazes na alocação dos parcos recursos e na prestação dos serviços. Ao colocarem-se como mediadores entre governo ou empresas privadas e populações alvo, aceitam a exigência de despolitização relativa da assistência social e filantrópica. Os movimentos sociais, nesta perspectiva, perdem seu papel de dinamizadores e impulsionadores das ONGS e passam a ser puramente clientes. Admite-se que o governo, sob a lógica do mercado, defina os espaços e objetivos dos agentes sociais e os controle. Ao subsumir tudo sob um "terceiro setor" estes agentes aceitam a diluição da distinção entre cidadania e filantropia, entre direito e caridade, verticalizando as relações que desde o racionalismo se horizontalizaram na forma de emancipação do indivíduo-cidadão.

Outra análise vê nas mudanças um incremento do associativismo e o ressurgimento de uma sociedade civil, cujo objetivo não é a conquista do poder do Estado, mas exercer influência política (Vieira, 1997; cf. Arato, Cohen, 1994). Ao lado da política e da economia estaria surgindo uma esfera pública não estatal, na qual os objetivos não estão associados à busca do lucro ou do poder, mas à solidariedade. Os movimentos sociais teriam sua atuação centrada nesta esfera, mas sem serem diferenciados numa ampla sociedade civil. Isso os deixa diluídos, sem abrir perspectivas para estratégias próprias e contextuais.

Enfocar a cidadania em suas múltiplas formas segundo esferas ou princípios específicos vigentes na sociedade dada abre para os movimentos sociais populares a perspectiva da via política da reforma permanente, do contrato social a ser constantemente renegociado. Exige realismo mesmo na utopia, mas permite ver ganhos e perdas nas suas reais dimensões e enfrentar opositores e aliados a partir das circunstâncias dadas e não de princípios atemporais. Uma via áurea para este fim não parece estar ainda traçada, mas o ponto de partida parece inequívoco: descolonizar os próprios movimentos sociais e suas onGs dos imperativos econômicos a que vêm cedendo espaço no processo de descentralização em curso no Brasil. 


\section{Referências bibliográficas}

ARATO, Andrew, COHEN, Jean. Sociedade civil e democratização. Belo Horizonte: Del Rez, 1994.

AROCENA, Felipe, LEÓN, Eduardo de. El complejo de Próspero: ensayos sobre cultura, modernidad y modernización en América Latina. Montevideo: Vintén, 1993.

BRESSER PEREIRA, Luiz Carlos, SPINK, Peter. Reforma do Estado e administraçäo pública gerencial. Rio de Janeiro: Fundação Getúlio Vargas, 1998.

DINIZ, Eli. Crise, reforma do Estado e governabilidade. Rio de Janeiro: Fundação Getúlio Vargas, 1997.

FERNANDES, Rubem César. Privado porém público: o terceiro setor na América Latina. 2 Aufl. Rio de Janeiro: Relume-Dumará, 1994.

GOHN, Maria da Glória. Os sem-terra, ONGS e cidadania. São Paulo: Cortez, 1997.

LESSA, Carlos et al. "Pobreza e política social: uma leitura da questão da exclusão nos anos 90". XXI Congresso da Associação Latino-Americana de Sociologia. São Paulo, 31 ago.-5 set. 1997.

MARSHALL, T. H. Cidadania, classe social e status. Rio de Janeiro: Zahar, 1967.

MORSE, Richard M. O espelho de próspero: cultura e idéias nas Américas. São Paulo: Companhia das Letras, 1988.

OFFE, Claus. "The present historical transition and some basic design options for societal institutions". Semináno Internacional Sociedade e a Reforma do Estado. São Paulo, 26-29 mar. 1998.

OLIVEIRA, Lucia Lippi de. "Anotações sobre um debate". Presença, Revista de Política e Cultura, n. 16 , p. 26-41, 1991.

PNUD, ed. Desenvolvimento, cooperação internacional e as ONGs. Rio de Janeiro: Ibase/Pnud, 1992.

SANTOS, Boaventura de Souza. Pela mão de Alice: o social e o político na pós-modernidade. 4. ed. São Paulo: Cortez, 1997.

SOBOTTKA, Emil Albert. Kirchliche entwicklungsprojekte in Brasilien: die Zusammenarbeit von Brot für die Welt und Evangelische Zentralstelle für Entwicklungshilfe mit der Coordenadoria Ecumênica de Serviço und der Evangelischen Kirche Lutherischen Bekenntnisses in Brasilien in der Förderung gesellschaftlicher Transformationsprozesse. Tese de Doutorado, Faculdade de Filosofia da Universidade de Münster, 1997.

STEIN, Rosa Helena. "A descentralização como instrumento de ação politica e suas controvérsias: revisão teórico-conceitual”. Serviço Social \& Sociedade, v. 18n n. 54, p. 75-96, jul. 1997.

VIEIRA, Liszt. Cidadania e globalização. Rio de Janeiro: Record, 1997. 